\title{
The Long-term Impacts of Birth Weight and Respiratory Complications after a Preterm Birth
}

Jennifer S Landry ${ }^{3,4}$, Zofia Zysman-Colman ${ }^{1}$, Suhair Bandeali ${ }^{2}$, Dan Croitoru ${ }^{3}$ and Geneviève M Tremblay ${ }^{3}$

${ }^{1}$ Faculty of Medicine, McGill University, Montreal (Quebec), Canada

${ }^{2}$ Faculty of Nursing, McGill University, Montreal (Quebec), Canada

${ }^{3}$ Respiratory Epidemiology \& Clinical Research Unit, Respiratory division, McGill University, Montreal (Quebec), Canada

${ }^{4}$ Department of Medicine, McGill University, Montreal (Quebec), Canada

*Corresponding author: Jennifer S. Landry, Montreal Chest Institute - McGill University Health Center, 3650 Avenue Saint-Urbain, Room K1.18, Montreal (Quebec), Canada, H2X 2P4, Tel: 1-514-934-1934 ext.32152; Fax: 1-514-843-2083; E-mail: jennifer.landry@mcgill.ca

Rec date: Feb 09, 2014, Acc date: Mar 24, 2014, Pub date: Mar 26, 2014

Copyright: ( 2014 Landry JS, et al. This is an open-access article distributed under the terms of the Creative Commons Attribution License, which permits unrestricted use, distribution, and reproduction in any medium, provided the original author and source are credited.

\begin{abstract}
Background: Infant respiratory distress syndrome (RDS) and bronchopulmonary dysplasia (BPD) remain important respiratory complications of preterm births. This study aims at establishing the incidence and impact of respiratory complications and extreme low birth weight (ELBW) on the healthcare utilization of a population of preterm infants.

Methods: Retrospective cohort study using administrative healthcare databases of the province of Quebec (Canada). The main outcome measures of healthcare utilization, hospital admissions, hospital mortality and use of prescription drugs were studied in 55033 subjects born prematurely with or without respiratory complications such as BPD or RDS between 1999 and 2009.

Results: Preterm infants with BPD and RDS had significantly higher hospital readmissions per person-year. This trend persisted for the entire duration of the 10-year follow-up. Diagnoses of childhood asthma, attention deficit hyperactivity disorder and cerebral palsy were more frequent in BPD subjects, but were not influenced by birth weight. Extreme low birth weight carried odds ratio of 38.0 [33.5, 43.2] and $3.5[3.2,3.9]$ respectively for the occurrence of BPD and RDS, and was associated with greater mortality, longer hospital stay and more medical visits per person-year. Except for anxiolytics and sedatives, bronchopulmonary dysplasia subjects were not more likely to have been prescribed neurological and psychiatric medications.
\end{abstract}

Conclusions: Birth weight is a major determinant in the occurrence of respiratory complications following a preterm birth. The impacts of BPD and extreme low birth weight following a preterm birth have lasting consequences on respiratory health and healthcare utilization.

Keywords: Bronchopulmonary dysplasia; infant respiratory distress syndrome; ICD-9 diagnostic codes; ICD-10 diagnostic codes; administrative databases

\section{Introduction}

Despite notable advances in prenatal and neonatal care, infant Respiratory Distress Syndrome (RDS) and Bronchopulmonary Dysplasia (BPD) remain important respiratory complications of preterm births, and their severity is influenced by birth weight [1]. RDS occurs in approximately $7 \%$ of all preterm infants [2] and typically affects preterm infants below 35 weeks of gestational age. The overall incidence of BPD at birth has not changed over the past decades [3], but is now infrequent in infants more than $1200 \mathrm{~g}$ of birth weight or with a gestational age exceeding 30 weeks [4]. In Canada, BPD will develop in about $20 \%$ of extreme premature infants and in $30 \%$ of infants with an extreme low birth weight (ELBW, less than 1 000g) [5].

This study aims to:
Establish the incidence and impact of respiratory complications on the healthcare utilization and prescription drug use of a population of preterm infants.

Study the impact of ELBW on outcomes in this population.

\section{Methods}

\section{Study design and selection of subjects}

This study was performed using a retrospective cohort of subjects born prematurely in the province of Quebec (Canada) between the years 1999 and 2009. This was accomplished using the administrative databases provided by the provincial health care system of Quebec (Canada), the Régie de l'assurance-maladie du Québec (RAMQ), which is the centralized health ministry responsible for insuring all residents in the province of Quebec and reimbursing the physicians, pharmacists and hospitals for care provided. The databases were used to identify all subjects born prematurely using the International Classification of Diseases codes for diagnoses, 9th revision (ICD-9) code: $765 .{ }^{* *}$ and ICD-10 code: P07.*. Subjects were first divided 
Page 2 of 8

based on the presence or absence of respiratory complications in the neonatal period using the diagnoses codes for either BPD (ICD-9 code: 770.7, ICD-10 code: P27.1) or RDS (ICD-9 code 769.*, ICD-10 code: P22.0, P22.8, P22.9, excluding P22.1 (transient tachypnea of the newborn)). Subjects were further divided based on their birth weight: ELBW (ICD codes: 765.0* and/or P07.0) and low birth weight (ICD codes $765.1^{\star}$ and/or P07.1).

A subset of subjects (validation cohort) from this retrospective cohort were matched to a previously described population of preterm infants admitted to the Montreal Children's Hospital, Montreal (Quebec), Canada, between January 1st 1999 and December 31st 2009 [6]. The population included all infants with preterm birth discharged with a diagnosis of BPD and/or RDS. This validation cohort was used to provide additional neonatal characteristics of the premature population such as exact birth weight, use of pulmonary surfactant and severity of BPD and to validate the use of the BPD diagnostic codes in the Quebec's administrative databases. A research ethics board of the McGill University Health Center approved this study and access to the RAMQ database was granted by the Commission d'accès à l'information du Québec.

\section{Administrative databases}

Four provincial databases administered by the RAMQ were used in this study:

MED-ECHO database [7]: Contains information on acute care hospitalizations and day surgeries performed in Quebec. Each record contains identifying demographic information along with the primary diagnosis on admission and 15 possible secondary diagnoses. This database was initiated April $1^{\text {st }} 1987$ and was used to obtain details on hospitalization, date of admission and length of stay as well as details on the admission, principal, and secondary diagnoses and cause of death when applicable.

Medical services database: Includes data on medical billing (type of service performed, specialty of claimant) as well as the number of claims and date on which the service was performed and the amount paid by the RAMQ to the billing physician. This database is complete starting January $1^{\text {st }} 1983$.

Registration database: Includes age, postal code, gender, and status (dead or alive) along with the date of death when applicable of all the persons insured by the RAMQ.

Pharmaceutical services database: Includes data on all drugs dispensed (date of service, DIN code, AHF class, dosage, duration), length of utilization and associated fees (service fees, contribution from the beneficiary and the amount covered by the RAMQ). It is complete starting January $1^{\text {st }} 1997$ for all children under 18 years of age insured under the RAMQ's drug plan. Data in this database have been validated and found to be accurate and reliable [8].

\section{Statistical analyses}

The resulting cohort was separated into three groups for all analyses:

Subjects born prematurely diagnosed with BPD (with or without an antecedent diagnosis of RDS).

Subjects born prematurely diagnosed with RDS but not BPD.

Subjects born prematurely who did not suffer from respiratory complications. Each group was further divided into two groups based on their birth weight: 1- ELBW and 2- Non-ELBW.

We examined characteristics associated with the occurrence of RDS and BPD, by comparing each group using univariate and multivariate approaches for adjustments of significant variables. One-way analysis of variance (ANOVA) or T-tests were used to compare means of continuous variables, and Mantel-Haenszel chi-square tests to compare ordinal variables. Tests based on the Poisson distribution were used for count and rate outcomes. To assess factors associated with severity of BPD, subjects with BPD included in the validation cohort were categorized as mild, moderate or severe, using the $\mathrm{NIH}$ consensus criteria [4]. An ordinal multinomial logistic regression using the CATMOD procedure [9] was used to determine the association of clinical factors and outcomes with disease severity among infants with BPD (mild and moderate versus severe BPD). Pvalues of $\leq 0.05$ were considered significant. Statistical analyses were conducted using SAS 9.2 statistical package (SAS Institute Inc., Cary, North Carolina, USA).

\section{Results}

\section{Characteristics of the study population}

55033 subjects were identified following a preterm birth between 1999 and 2009, representing approximately 7\% of all live births in the province of Quebec for that period. Table 1 shows the characteristics of the study population. Male infants were found to suffer from respiratory complications more frequently following a preterm birth (odds ratio (OR) for BPD if male: 1.51 [95\% confidence interval (CI): 1.34, 1.69], OR for RDS if male: 1.42 [95\% CI: 1.34 , $1.50])$.

\begin{tabular}{|c|c|c|c|c|}
\hline & BPD & RDS & Preterm & $\mathrm{p}$-value \\
\hline $\mathrm{n}$ & 1257 & 6270 & 47506 & - \\
\hline Age in 2011 , in years & $7.1(3.1)$ & $5.9(3.1)$ & $6.8(3.2)$ & - \\
\hline Male gender & $765(60.9)$ & $3773(60.2)$ & $24556(51.7)$ & $<0.0001$ \\
\hline Mortality & $48(3.8)$ & $315(5.0)$ & $1032(2.2)$ & $<0.0001$ \\
\hline \multicolumn{5}{|c|}{ Other diagnoses (perinatal period) } \\
\hline Necrotizing enterocolitis & $135(10.7)$ & $147(2.3)$ & $190(0.4)$ & $<0.0001$ \\
\hline Patent ductus arteriosus & $654(52.0)$ & $790(12.6)$ & $1090(2.3)$ & $<0.0001$ \\
\hline
\end{tabular}


Citation: Landry JS, Zysman-Colman Z, Bandeali S, Croitoru D, Tremblay MG (2014) The Long-term Impacts of Birth Weight and Respiratory Complications after a Preterm Birth. J Neonatal Biol 3: 128. doi:10.4172/2167-0897.1000128

Page 3 of 8

\begin{tabular}{|c|c|c|c|c|}
\hline Retinopathy of prematurity & $594(47.3)$ & $535(8.5)$ & $449(0.9)$ & $<0.0001$ \\
\hline Intraventricular/intracerebral hemorrhage & $227(18.1)$ & $360(5.7)$ & $363(0.8)$ & $<0.0001$ \\
\hline Anoxic encephalopathy & $341(27.1)$ & $995(15.9)$ & $3617(7.6)$ & $<0.0001$ \\
\hline Pneumothorax & $16(1.3)$ & $158(2.5)$ & $48(0.1)$ & $<0.0001$ \\
\hline Pulmonary interstitial emphysema & $80(6.4)$ & $240(3.8)$ & $177(0.4)$ & $<0.0001$ \\
\hline Apnea of prematurity & $307(24.4)$ & $1080(17.2)$ & $1737(3.7)$ & $<0.0001$ \\
\hline Neonatal sepsis & $470(37.4)$ & $1097(17.5)$ & $2128(4.5)$ & $<0.0001$ \\
\hline \multicolumn{5}{|l|}{ Diagnoses (post-perinatal) } \\
\hline Childhood asthma & $626(49.8)$ & $1723(27.5)$ & $11379(23.9)$ & $<0.0001$ \\
\hline Cor pulmonale/pulmonary hypertension & $53(4.2)$ & $20(0.3)$ & $63(0.1)$ & $<0.0001$ \\
\hline Attention deficit hyperactivity disorder & $107(8.5)$ & $279(4.5)$ & $2117(4.5)$ & $<0.0001$ \\
\hline Cerebral palsy & $84(6.7)$ & $90(1.4)$ & $167(0.4)$ & $<0.0001$ \\
\hline
\end{tabular}

Table 1: Characteristics of preterm subjects with or without respiratory complications born in Quebec between 1999 and $2009^{\star}$

Diagnosis of asthma, attention-deficit hyperactivity disorder (ADHD) and cerebral palsy were found to be statistically more frequent in the BPD group.

\section{Healthcare utilization, hospital admissions and hospital mortality}

Table 2 illustrates the length of stay and hospital mortality at birth following a preterm birth and for subsequent hospital readmissions.

\begin{tabular}{|c|c|c|c|c|}
\hline & BPD & RDS & Preterm & p-value \\
\hline \multicolumn{5}{|l|}{ Hospital admission at birth } \\
\hline Length of stay, days (median) & 84 & 16.5 & 5 & $<0.0001$ \\
\hline \multicolumn{5}{|l|}{ Type of deaths } \\
\hline Peri-operative death & $2(0.2)$ & $1(0.02)$ & $1(0.002)$ & - \\
\hline Maternal death & 0 & 0 & 0 & - \\
\hline Other type & $14(1.1)$ & $6(0.1)$ & $17(0.04)$ & - \\
\hline Early neonatal death $†$ & $2(0.2)$ & $135(2.2)$ & $900(0.02)$ & - \\
\hline Late neonatal death $\dagger$ & $6(0.5)$ & $42(0.7)$ & $18(0.04)$ & - \\
\hline \multicolumn{5}{|c|}{ Hospital admissions following discharge after birth } \\
\hline Total of subjects with a least one admission & $1257(100)$ & $6270(100)$ & $47506(100)$ & - \\
\hline Total number of admissions & 4763 & 13406 & 86176 & - \\
\hline Number of admissions/person-year & $1.74(0.05)$ & $1.40(0.07)$ & $1.21(0.03)$ & $<0.0001$ \\
\hline Length of stay, days (median) & 4 & 3 & 3 & $<0.0001$ \\
\hline \multicolumn{5}{|l|}{ Type of deaths } \\
\hline Pre/peri-operative death & 0 & 0 & $3(0.006)$ & - \\
\hline Post-operative death & $1(0.1)$ & $2(0.03)$ & $7(0.01)$ & - \\
\hline
\end{tabular}

The number of visits per person-year to a general practitioner did not differ between the three groups but the number of visits per personyear to a specialist was significantly higher in the BPD population compared to the RDS (2-fold higher) and preterm groups (four-fold higher) (data not shown). The rate of hospitalization after the initial hospital discharge remained relatively constant throughout the duration of follow-up, up to age 10 for each group as seen in Figure 1. 
Citation: Landry JS, Zysman-Colman Z, Bandeali S, Croitoru D, Tremblay MG (2014) The Long-term Impacts of Birth Weight and Respiratory Complications after a Preterm Birth. J Neonatal Biol 3: 128. doi:10.4172/2167-0897.1000128

Page 4 of 8

\begin{tabular}{|c|c|c|c|c|}
\hline Other type & $19(1.5)$ & $35(0.6)$ & 0 & - \\
\hline Early neonatal death§ & 0 & 0 & 0 & - \\
\hline Late neonatal death§ & 0 & $42(0.7)$ & $29(0.06)$ & - \\
\hline
\end{tabular}

Table 2: Hospital admissions, length of stay and hospital mortality of preterm subjects born in Quebec between 1999 and $2009^{*}$

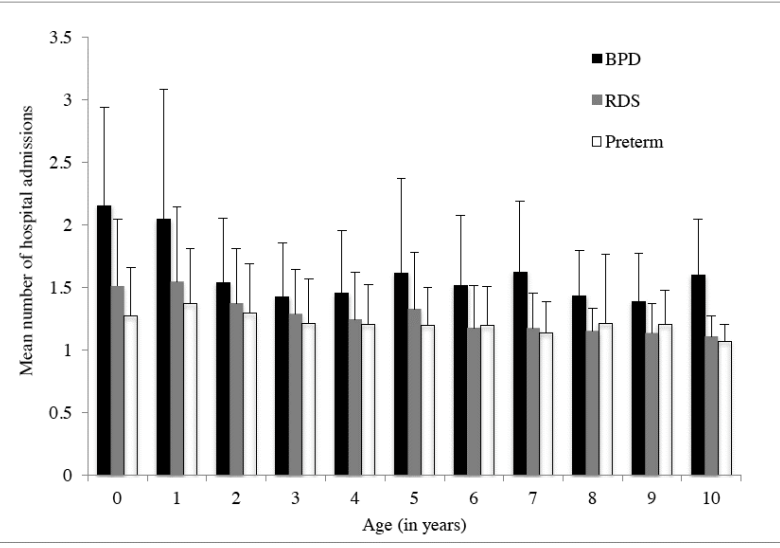

\section{Effects of birth weight on outcomes}

Birth weight is a major determinant in the occurrence of respiratory complications following a preterm birth as seen in Table 3. The presence of ELBW was significantly associated with greater mortality, longer hospital length of stay and more medical visits per person-year. ELBW carried an OR of 38.0 [95\% CI: 33.5, 43.2] for the occurrence of BPD and an OR of 3.5 [95\% CI: 3.2, 3.9] for the occurrence of RDS. Despite more male infants suffering from respiratory complications, they were not more likely to be of $\operatorname{ELBW}(0.96$ [0.89, 1.03]). Birth weight was not associated with a difference in post-natal diagnoses of childhood asthma, ADHD and cerebral palsy.

Figure 1: Mean number of hospital admission of preterm subjects by age. (The error bars represent the standard deviation of the mean. $\mathrm{BPD}=$ Bronchopulmonary dysplasia; RDS=Respiratory distress syndrome.)

\begin{tabular}{|c|c|c|c|c|c|c|c|c|c|}
\hline & \multicolumn{3}{|l|}{ BPD } & \multicolumn{3}{|l|}{ RDS } & \multicolumn{3}{|l|}{ Preterm } \\
\hline & ELBW & Non-ELBW & $\mathrm{p}$-value & ELBW & $\begin{array}{l}\text { Non- } \\
\text { ELBW }\end{array}$ & $\mathrm{p}$-value & ELBW & Non-ELBW & $\mathrm{p}$-value \\
\hline $\mathrm{n}$ & 801 & 434 & - & 771 & 4478 & - & 1613 & 33248 & - \\
\hline Male gender & $454(56.7)$ & $296(68.2)$ & $<0.0001$ & $420(54.5)$ & $\begin{array}{l}2693 \\
(60.1)\end{array}$ & 0.003 & $818(50.7)$ & $\begin{array}{l}16848 \\
(50.7)\end{array}$ & 0.97 \\
\hline Mortality & $40(5.0)$ & $8(1.8)$ & 0.006 & $160(20.8)$ & $127(2.8)$ & $<0.0001$ & $600(37.2)$ & $330(9.9)$ & $<0.0001$ \\
\hline Age of death, in months & $5.97(13.5)$ & $2.25(2.9)$ & 0.35 & $0.68(1.6)$ & $4.02(8.6)$ & $<0.0001$ & $0.05(0.4)$ & $8.44(20.9)$ & $<0.0001$ \\
\hline $\begin{array}{l}\text { Number of admissions/person- } \\
\text { year }\end{array}$ & $1.73(0.06)$ & $1.76(0.1)$ & 0.30 & $1.41(0.1)$ & $1.41(0.1)$ & 0.44 & $1.26(0.1)$ & $1.22(0.02)$ & 0.10 \\
\hline Length of stay, days (median) & 99 & 70 & $<0.0001$ & 36 & 17 & $<0.0001$ & 4 & 6 & $<0.0001$ \\
\hline $\begin{array}{l}\text { Number medical visits/person- } \\
\text { year (mean, SD) }\end{array}$ & $\begin{array}{l}33.93 \\
(12.64)\end{array}$ & $\begin{array}{l}26.37 \\
(11.07)\end{array}$ & $<0.0001$ & $\begin{array}{l}18.06 \\
(7.10)\end{array}$ & $\begin{array}{l}13.88 \\
(4.32)\end{array}$ & $<0.0001$ & $\begin{array}{l}11.64 \\
(3.10)\end{array}$ & $9.07(1.69)$ & $<0.0001$ \\
\hline \multicolumn{10}{|l|}{ Diagnoses (post-natal) } \\
\hline Childhood asthma & $390(48.7)$ & $228(52.5)$ & 0.19 & $207(26.9)$ & $\begin{array}{l}1347 \\
(30.1)\end{array}$ & 0.06 & $361(22.4)$ & $8989(27.0)$ & $<0.0001$ \\
\hline $\begin{array}{l}\text { Attention deficit hyperactivity } \\
\text { disorder }\end{array}$ & $63(7.9)$ & $\begin{array}{l}41 \\
(9.5)\end{array}$ & 0.33 & $40(5.2)$ & $222(4.9)$ & 0.78 & $91(5.6)$ & $1740(5.2)$ & 0.47 \\
\hline Cerebral palsy & $55(6.9)$ & $28(6.5)$ & 0.78 & $15(1.9)$ & $72(1.6)$ & 0.49 & $16(0.9)$ & $135(0.4)$ & 0.0005 \\
\hline
\end{tabular}


Citation: Landry JS, Zysman-Colman Z, Bandeali S, Croitoru D, Tremblay MG (2014) The Long-term Impacts of Birth Weight and Respiratory Complications after a Preterm Birth. J Neonatal Biol 3: 128. doi:10.4172/2167-0897.1000128

Page 5 of 8

* Values expressed in: $\mathrm{n}(\%)$ or mean ( \pm standard deviation). BPD=Bronchopulmonary dysplasia; ELBW= extreme low birth weight; non-ELBW= non-extreme low birth weight; RDS=Respiratory distress syndrome; SD=standard deviation.

Table 3: Characteristics of preterm infants with or without respiratory complications based on birth weight*

\section{Patterns of use of prescription drugs}

The pattern of use of prescription drugs did not differ based on the presence of ELBW (data not shown) but was significantly different, with a tendency for greater number of prescriptions per person-year and longer duration of treatment for antibiotics and respiratory drugs in the BPD group compared to both the RDS and the preterm groups
(Table 4). Although their use differed amongst the 3 groups, BPD subjects were not more likely to have been prescribed neurological and psychiatric medications used for the treatment of cerebral palsy, epilepsy and ADHD than the RDS or preterm subjects, except for anxiolytics and sedatives.

\begin{tabular}{|c|c|c|c|c|c|c|c|c|c|c|}
\hline \multirow[b]{2}{*}{$\begin{array}{l}\text { Drug groups (and a list } \\
\text { of the most common } \\
\text { drugs used in each } \\
\text { class) }\end{array}$} & \multicolumn{3}{|c|}{ BPD subjects $(n=1604)^{*}$} & \multicolumn{3}{|c|}{ RDS subjects $(n=8316)^{*}$} & \multicolumn{3}{|c|}{ Preterm subjects $(n=60103)^{*}$} & \multirow[t]{2}{*}{$p$-value $\dagger$} \\
\hline & $\begin{array}{l}\text { Number of } \\
\text { subjects } \ddagger\end{array}$ & $\begin{array}{l}\text { Prescriptio } \\
\text { ns/person- } \\
\text { year }\end{array}$ & $\begin{array}{l}\text { Duration(da } \\
\text { ys/person- } \\
\text { year)§ }\end{array}$ & $\begin{array}{l}\text { Number of } \\
\text { subjectsł }\end{array}$ & $\begin{array}{l}\text { Prescriptio } \\
\text { ns/person- } \\
\text { year }\end{array}$ & $\begin{array}{l}\text { Duration(da } \\
\text { ys/person- } \\
\text { year)§ }\end{array}$ & $\begin{array}{l}\text { Number of } \\
\text { subjectsł }\end{array}$ & $\begin{array}{l}\text { Prescriptio } \\
\text { ns/person- } \\
\text { year }\end{array}$ & $\begin{array}{l}\text { Duration(da } \\
\text { ys/person- } \\
\text { year)§ }\end{array}$ & \\
\hline \multicolumn{11}{|l|}{ Anti-infectious drugs } \\
\hline \multirow[t]{2}{*}{ Antibiotics } & $\begin{array}{l}493 \\
(30.7)\end{array}$ & 2.6 & 26.2 & $1733(20.8)$ & 2.5 & 23.6 & $15450(25.7)$ & 2.3 & 21.0 & $<0.0001$ \\
\hline & \multicolumn{9}{|c|}{ Clarithromycin, Cephalosporin } & \\
\hline \multicolumn{11}{|l|}{ Respiratory drugs } \\
\hline \multirow[t]{2}{*}{ Sympathomimetics } & $\begin{array}{l}393 \\
(24.5)\end{array}$ & 2.7 & 63.7 & $1055(12.7)$ & 2.0 & 48.4 & $7782(12.9)$ & 1.9 & 44.9 & $<0.0001$ \\
\hline & \multicolumn{9}{|l|}{ Salbutamol } & \\
\hline \multirow[t]{2}{*}{ Inhaled corticosteroids } & $\begin{array}{l}419 \\
(26.1)\end{array}$ & 3.0 & 74.8 & $1122(13.5)$ & 2.3 & 56.2 & $\begin{array}{l}8548 \\
(14.2)\end{array}$ & 2.2 & 53.9 & $<0.0001$ \\
\hline & \multicolumn{9}{|l|}{ Fluticasone } & \\
\hline \multicolumn{11}{|c|}{ Neurological and Psychiatric drugs } \\
\hline \multirow[t]{2}{*}{$\begin{array}{l}\text { Skeletal } \\
\text { relaxants }\end{array}$} & $\begin{array}{l}3 \\
(0.2)\end{array}$ & 10.8 & 263.6 & $\begin{array}{l}5 \\
(0.1)\end{array}$ & 12.3 & 216.1 & $\begin{array}{l}11 \\
(0.02)\end{array}$ & 8.7 & 245.3 & 0.001 \\
\hline & \multicolumn{9}{|l|}{ Baclofen } & \\
\hline \multirow[t]{2}{*}{ Anticonvulsants } & $\begin{array}{l}18 \\
(1.1)\end{array}$ & 10.7 & 270.2 & $\begin{array}{l}35 \\
(0.4)\end{array}$ & 20.0 & 412.9 & $176(0.3)$ & 12.4 & 333.4 & $<0.0001$ \\
\hline & \multicolumn{9}{|c|}{ Clobazam, Valproic acid } & \\
\hline \multirow[t]{2}{*}{$\begin{array}{l}\text { Antidepressants, } \\
\text { antipsychotics }\end{array}$} & $\begin{array}{l}6 \\
(0.4)\end{array}$ & 9.4 & 281.6 & $\begin{array}{l}14 \\
(0.2)\end{array}$ & 9.9 & 267.7 & $174(0.3)$ & 12.2 & 270.1 & $<0.0001$ \\
\hline & \multicolumn{9}{|c|}{ Risperidone, Trazodone, Quetiapine } & \\
\hline \multirow[t]{2}{*}{$\begin{array}{l}\text { Anxiolytics, sedatives } \\
\text { and hypnotics }\end{array}$} & $\begin{array}{l}54 \\
(3.4)\end{array}$ & 2.4 & 40.7 & $135(1.6)$ & 2.2 & 28.1 & $1237(2.1)$ & 1.7 & 25.8 & $<0.0001$ \\
\hline & \multicolumn{9}{|c|}{ Hydroxyzine, Nitrazepam } & \\
\hline \multirow[t]{2}{*}{ Cerebral stimulants } & $\begin{array}{l}46 \\
(2.9)\end{array}$ & 6.4 & 180.3 & $113(1.4)$ & 8.5 & 212.8 & $995(1.7)$ & 8.8 & 224.7 & $<0.0001$ \\
\hline & \multicolumn{9}{|c|}{ Methylphenidate, Dexamphetamine } & \\
\hline
\end{tabular}

The number in brackets indicates the mean number of subjects included in the database over the 11 year-period, $† p$-value associated with the differences observed between the numbers of prescriptions issued per person-year between the three groups; $\ddagger$ The number indicates the total number of subjects who received the drug, 
Citation: Landry JS, Zysman-Colman Z, Bandeali S, Croitoru D, Tremblay MG (2014) The Long-term Impacts of Birth Weight and Respiratory Complications after a Preterm Birth. J Neonatal Biol 3: 128. doi:10.4172/2167-0897.1000128

Page 6 of 8

followed in brackets, by the percentage over the total number of subjects in the groups;§Meanduration of therapy per person-year, values expressed in days and limited to those subjects whom the drug was dispensed to (this is also valid for the number of prescription/person-year, calculated only for the subjects taking the drug); BPD=Bronchopulmonary dysplasia; RDS=Respiratory distress syndrome.

Table 4: Prescription drugs use in preterm subjects born in Quebec between 1999 and 2009

\section{Characteristics of the validation cohort and validation of the diagnostic codes for BPD}

830 subjects with BPD and RDS from the Montreal Children's Hospital cohort were matched with the MED-ECHO database. Table 5 describes the characteristics of the matched population, including the prevalence of antenatal administration of beta-methasone for lung maturation in the setting of preterm labor and the use of pulmonary surfactant in infants suffering from respiratory complications. The OR, adjusted for male gender, gestational age and birth weight, for developing BPD were 0.85 [95\% CI: 0.80, 0.92] for each additional $100 \mathrm{~g}$ of birth weight and 0.96 [95\% CI: 0.94, 0.98] for each additional day of gestation. Despite correcting for gestational age and birth weight, the adjusted OR for the occurrence of BPD was 2.52 [95\% CI: $1.41,4.51]$ with prenatal beta-methasone administration and 1.07
[95\% CI: $0.70, \quad 1.63]$ with postnatal pulmonary surfactant administration More severe disease was associated with a shorter gestational age (adjusted OR for severe versus mild BPD and severe versus moderate BPD: 0.97 [95\% CI: 0.94, 0.99] for each additional day of gestation), and a lower birth weight as well (adjusted OR for severe versus mild BPD: 0.84 [95\% CI: 0.75, 0.95] and adjusted OR for severe versus moderate BPD: 0.88 [95\% CI: 0.78, 0.97] for each additional 100 $\mathrm{g}$ of birth weight) when adjusted for gestational age, birth weight, male gender and use of pulmonary surfactant. Pulmonary surfactant use was found to only be significant when comparing the odds of developing severe versus mild BPD with an adjusted OR of 1.92 [95\% CI: 1.08, 3.39]. The use of the ICD-9 and ICD-10 diagnostic codes for BPD in the MED-ECHO database had a specificity of $96.0 \%$ and a sensitivity of $82.1 \%$.

\begin{tabular}{|c|c|c|c|}
\hline & BPD & RDS & $p$-value \\
\hline Gestational age, in days & $187.9(18.3)$ & $236.1(19.3)$ & $<0.0001$ \\
\hline Birth weight, in grams & $950.0(410.0)$ & $2281.0(670.0)$ & $<0.0001$ \\
\hline Apgar score at 1-minute & $4.6(2.4)$ & $6.7(2.5)$ & $<0.0001$ \\
\hline Apgar score at 5-minute & $6.7(1.9)$ & $8.1(1.9)$ & $<0.0001$ \\
\hline Maternal age, in years & $29.81(6.2)$ & $28.79(5.5)$ & 0.02 \\
\hline \multicolumn{4}{|l|}{ Gestation } \\
\hline single & $328(73.9)$ & $316(89.8)$ & \multirow[t]{3}{*}{$<0.0001$} \\
\hline twins & $96(21.6)$ & $33(9.4)$ & \\
\hline triplets & $20(4.5)$ & $3(0.9)$ & \\
\hline Prenatal beta-methasone administration & $284(63.9)$ & $76(21.6)$ & $<0.0001$ \\
\hline Post-natal surfactant administration & $290(65.5)$ & $182(51.7)$ & $<0.0001$ \\
\hline \multicolumn{4}{|l|}{ BPD severity† } \\
\hline Mild & $97(21.9)$ & & \\
\hline Moderate & $184(41.6)$ & & \\
\hline Severe & $126(28.5)$ & & \\
\hline
\end{tabular}

Table 5: Neonatal characteristics of the matched population*

\section{Discussion}

\section{Incidence and impact of respiratory complications on outcomes}

A higher prevalence of childhood asthma in BPD and RDS subjects compared to the general pediatric population has been described previously $[10,11]$ and the presence of airway hyper responsiveness was previously brought forward as an important factor in the development and severity of BPD [12,13]. Similarly, low birth weight and prematurity have also been shown to lead to impaired lung development and pulmonary dysfunction and an increased asthma risk $[14,15]$. The prevalence of childhood asthma documented in the BPD and RDS subjects in this study is higher than previously documented in a similarly selected cohort composed of "old" BPD and RDS subjects born between 1983 and 1992 [16]. The observed difference could possibly be accounted for by the more profound degree of prematurity and lower birth weight of this current cohort. 
Page 7 of 8

Indeed, the infants who suffered from BPD born after 1999 were in average 7 days more premature and weighed $140 \mathrm{~g}$ less than their counter part born a decade earlier.

Interestingly, the number of hospital readmissions remained constant until age 10 in all preterm subjects, with or without the occurrence of respiratory complications. This is different than initially documented by Baraldi et al. where it was observed that the rate of hospitalization dropped after the age of 2 years as a direct influence of respiratory syncytial virus infections occurring in early childhood [17]. It is however similar to what was previously subjects reported in a retrospective study of BPD and RDS over a 25 year follow-up period [18]. This observed trend might impact significantly on healthcare utilization and cost as the number of preterm births continues to increase.

The greater tendency for BPD subjects to have been prescribed antibiotics and respiratory drugs points to the persistence of respiratory symptoms and limitations in about 24 to $26 \%$ of BPD subjects, which is double what is observed in the RDS and preterm groups. Fortunately, the presence of respiratory complications such as BPD and RDS does not seem to influence the need for prescription drugs for neurological and psychiatric disorders later on in life, except for anxiolytics and sedatives in BPD subjects.

\section{Impact of ELBW}

Male gender has long been known to be a risk factor for prematurity and respiratory complications $[1,19,20]$ and ELBW has been associated with more frequent respiratory complications, so it is interesting to note that despite male infants suffering more frequently from respiratory complications, they were not more likely to be of ELBW.

The lower risk for female infants to develop respiratory complications is likely explained by their more mature phospholipid profile during the saccular phase of lung development (between 26 and 36 weeks of gestation), a result of an earlier production of surfactant [21]. However, female gender has not been found to be a protective factor in infants born before 25 weeks [22] and suggests that the disadvantage of male gender is not observed with ELBW since most of ELBW infants are born in the pre-saccular phase.

As expected, mortality was strongly associated with the presence of ELBW across the three groups of study subjects but the presence of ELBW did not discriminate for the occurrence of childhood asthma, ADHD and cerebral palsy later in life.

\section{Impact of use of antenatal corticosteroids and pulmonary surfactant}

The use of antenatal corticosteroids has been questioned before with regards to its associated increased risk of developing BPD and chronic diseases later in life [23] resulting from an initial suppression followed by an augmentation of the inflammatory responses of fetal monocytes [24,25]. This is supported by the finding of an almost double risk of BPD in the group exposed to beta-methasone when birth weight and degree of prematurity are taken into account. The lack of association between the use of pulmonary surfactant with the development of BPD found in this study has been shown by others $[9,26,27]$ but it is interesting to see that the more severe form of BPD was reduced in favor of milder disease with its use.

\section{Strengths and limitations}

The main limitation of this study is the use of hospital discharge diagnoses (MED-ECHO) and medical billing diagnoses as surrogate for diagnoses of medical complications related to preterm births. The MED-ECHO databases have been previously validated and found to be reliable for a variety of diagnoses but the use of medical billing diagnoses has only been validated for BPD $[8,28]$. This constitutes a weakness when studying the prevalence of diseases such as childhood asthma, ADHD and cerebral palsy. The universal coverage for healthcare in the province of Quebec is strength of this study, especially since prematurity is often observed in lower socioeconomic stratum, a factor linked to prematurity [29]. Since the pharmaceutical database used in this study is considered complete as of January 1st 1997 and all individuals below the age of 18 had free and universal coverage for prescription drugs, we likely have a correct estimate of the utilization of medications for the complete study population.

The impact of bronchopulmonary dysplasia following a preterm birth has lasting consequences on respiratory health, healthcare utilization and prescription drug use. These long-term observations are further reinforced by the presence of ELBW, a variable strongly associated with the occurrence of BPD and RDS and greater healthcare utilization.

\section{Funding}

This study was supported by a grant from the Canadian Institutes of Health Research and from the Réseau en Santé Respiratoire - Fonds de la recherche en santé du Québec.

\section{References}

1. Landry JS, Menzies D (2011) Occurrence and severity of bronchopulmonary dysplasia and respiratory distress syndrome after a preterm birth. Paediatr Child Health 16: 399-403.

2. Hermansen CL, Lorah KN (2007) Respiratory distress in the newborn. Am Fam Physician 76: 987-994.

3. Smith VC, Zupancic JA, McCormick MC, Croen LA, Greene J, et al. (2005) Trends in severe bronchopulmonary dysplasia rates between 1994 and 2002. J Pediatr 146: 469-473.

4. Jobe AH, Bancalari E (2001) Bronchopulmonary dysplasia. Am J Respir Crit Care Med 163: 1723-1729.

5. Lemons JA, Bauer CR, Oh W (2001) Very low birth weight outcomes of the National Institute of Child health and human development neonatal research network, January 1995 through December 1996. NICHD Neonatal Research Network. Pediatrics 107:E1.

6. Zysman-Colman Z, Tremblay G, Bandeali S, Croitoru D, Landry JS (2012) Bronchopulmonary dysplasia, trends over three decades. McGill J Med 18:86-90

7. Ministere de sante du Quebec (2009) CADRE NORMATIF DU SYSTE 'ME MED-E'CHO

8. Tamblyn R, Lavoie G, Petrella L, Monette J (1995) The use of prescription claims databases in pharmacoepidemiological research: the accuracy and comprehensiveness of the prescription claims database in Québec. J Clin Epidemiol 48: 999-1009.

9. Rush MG, Hazinski TA (1992) Current therapy of bronchopulmonary dysplasia. Clin Perinatol 19: 563-590.

10. Eber E, Zach MS (2001) Long term sequelae of bronchopulmonary dysplasia (chronic lung disease of infancy). Thorax 56: 317-323.

11. Hung YL, Hsieh WS, Chou HC, Yang YH, Chen CY, et al. (2010) Antenatal steroid treatment reduces childhood asthma risk in very low birth weight infants without bronchopulmonary dysplasia. J Perinat Med 38:95-102 
Citation: Landry JS, Zysman-Colman Z, Bandeali S, Croitoru D, Tremblay MG (2014) The Long-term Impacts of Birth Weight and Respiratory Complications after a Preterm Birth. J Neonatal Biol 3: 128. doi:10.4172/2167-0897.1000128

Page 8 of 8

12. Goldman SL, Gerhardt T, Sonni R, Feller R, Hehre D, et al. (1983) Early prediction of chronic lung disease by pulmonary function testing. Pediatr 102: 613-617.

13. Motoyama EK, Fort MD, Klesh KW, Mutich RL, Guthrie RD (1987) Early onset of airway reactivity in premature infants with bronchopulmonary dysplasia. Am Rev Respir Dis 136: 50-57.

14. McLeod A, Ross P, Mitchell S, Tay D, Hunter L, et al. (1996) Respiratory health in a total very low birthweight cohort and their classroom controls. Arch Dis Child 74: 188-194.

15. McCormick MC, Brooks-Gunn J, Workman-Daniels K, Turner J, Peckham GJ (1992) The health and developmental status of very lowbirth-weight children at school age. JAMA 267: 2204-2208.

16. Landry JS, Croitoru D, Jin Y, Schwartzman K, Benedetti A, et al. (2012) Health care utilization by preterm infants with respiratory complications in Quebec. Can Respir J 19: 255-260.

17. Baraldi E, Carraro S, Filippone M (2009) Bronchopulmonary dysplasia: definitions and long-term respiratory outcome. Early Hum Dev 85: S1-3.

18. Landry JS, Croitoru D, Jin Y, Schwartzman K, Benedetti A, et al. (2012) Health care utilization by preterm infants with respiratory complications in Quebec. Can Respir J 19: 255-260.

19. Landry JS, Chan T, Lands L, Menzies D (2011) Long-term impact of bronchopulmonary dysplasia on pulmonary function. Can Respir J 18: 265-270.

20. Teune MJ van Wassenaer AG, van Buuren S, Mol BW, Opmeer BC Dutch POPS Collaborative Study Group (2012) Perinatal risk-indicators for long-term respiratory morbidity among preterm or very low birth weight neonates. Eur J Obstet Gynecol Reprod Biol 163: 134-141.
21. Fleisher B, Kulovich MV, Hallman M, Gluck L (1985) Lung profile: sex differences in normal pregnancy. Obstet Gynecol 66: 327-330.

22. Henderson-Smart DJ, Hutchinson JL, Donoghue DA, Evans NJ, Simpson JM, et al. (2006) Prenatal predictors of chronic lung disease in very preterm infants. Arch Dis Child Fetal Neonatal Ed 91: F40-45.

23. Asztalos E (2012) Antenatal corticosteroids: a risk factor for the development of chronic disease. J Nutr Metab 2012: 930591.

24. Askin DF, Diehl-Jones W (2009) Pathogenesis and prevention of chronic lung disease in the neonate. Crit Care Nurs Clin North Am 21: 11-25, v.

25. Kallapur SG, Bachurski CJ, Le Cras TD, Joshi SN, Ikegami M, et al. (2004) Vascular changes after intra-amniotic endotoxin in preterm lamb lungs. Am J Physiol Lung Cell Mol Physiol 287: L1178-1185.

26. Donn SM, Dalton J (2009) Surfactant replacement therapy in the neonate: beyond respiratory distress syndrome. Respir Care 54: 1203-1208.

27. Pinkerton KE, Ikegami M, Dillard LM, Jobe AH (2000) Surfactant treatment effects on lung structure and type II cells of preterm ventilated lambs. Biol Neonate 77: 243-252.

28. Landry JS, Croitoru D, Menzies D (2012) Validation of ICD-9 diagnostic codes for bronchopulmonary dysplasia in Quebec's provincial health care databases. Chronic Dis Inj Can 33: 47-52.

29. Kramer MS, Goulet L, Lydon J, Séguin L, McNamara H, et al. (2001) Socio-economic disparities in preterm birth: causal pathways and mechanisms. Paediatr Perinat Epidemiol 15 Suppl 2: 104-123.

30. Canada S (2011) Leading causes of death, infants, by sex, Canada. 